

\title{
PENGARUH LAMA MELAUT, KEKUATAN MESIN TEMPEL, DAN KARAKTERISTIK RESPONDEN TERHADAP PENDAPATAN NELAYAN TANGKAP TRADISIONAL DI KABUPATEN TAKALAR
}

\section{(The Influence of Fishing Time, Power Outboard Engine, and Respondent Characteristics to Income of Traditional Catch Fishermen in Takalar District)}

\author{
A. Rahim ${ }^{1 *}$, D.R.D. Hastuti ${ }^{1}$, dan A. Syahma ${ }^{1}$, Firmansyah ${ }^{2}$ \\ ${ }^{1}$ Program Studi Ekonomi Pembangunan Fakultas Ekonomi Universitas Negeri Makassar \\ ${ }^{2}$ Program Studi Agribisnis Fakultas Pertanian Universitas Muhammadiyah Makassar \\ *Email : abd.rahim@unm.ac.id
}

Diterima 24 Februari 2018, disetujui 28 April 2018

\begin{abstract}
ABSTRAK
Perubahan musim di Perairan Selat Makassar yang berbatasan langsung dengan wilayah pesisir pantai Barat Kabupaten Takalar mengakibatkan perubahan jumlah tangkapan sehingga berdampak pada pendapatan usaha tangkapnya. Penelitian ini bertujuan menganalisis pengaruh lama melaut, kekuatan mesin tempel, karakteristik respoden terhadap pendapatan nelayan tangkap. Analisis data menggunakan Ordiary Least Square (OLS) dari data cross-section yang bersumber dari data primer Tahun 2016. Hasil penelitian menunjukkan bahwa lama melaut dan ukuran kekuatan mesin tempel berpengaruh positif terhadap pendapatan nelayan tangkap tradisional di Kabupaten Takalar. Sedangkan karakteristik respoden berupa umur, pendidikan terakhir, tanggungan keluarga, dan pengalaman melaut tidak berpengaruh terhadap pendapatan nelayan tangkap tradisional.
\end{abstract}

Kata kunci: pendapatan, nelayan, tradisional

\begin{abstract}
The changing seasons in the Makassar Strait bordering the west coast of Takalar District caused a change in the number of catches and incomes This study aimed to analyze the influence of sailing duration, outboard engine power, and characteristic of respondents. Data analysis used Ordinary Least Square (OLS) from cross-sectional data 2016. The result of research shows that the sailing duration and the size of outboard engine power have positive effect to the income of traditional fisherman in Takalar District. While the age, education, number of family dependents, and the experience has no effect on the income of traditional fishermen.
\end{abstract}

Keywords: fisherman, income, traditional

\section{PENDAHULUAN}

Peran nelayan tradisional mendukung mata pencaharian dan kesejahteraan lebih dari
500 juta orang di seluruh dunia dan sebagai sumber penting pendapatan di negara-negara berkembang (Barnes-Mauthe et al. 2013). 
Sebagian besar nelayan tangkap tradisional di Indonesia ditemukan di wilayah pesisir (Winarti dan Permadi, 2015) dan menjadi salah satu sumber pendapatan penting utama di negara-negara berkembang (Pomeroy dan Andrew, 2011) serta sebagai bagian pembangunan ekonomi wilayah pesisir (Israel et al. 2004).

Nelayan tradisional terdiri dari perahu motor tempel dan perahu tanpa motor sedangkan nelayan modern adalah yang menggunakan kapal motor (Gebremedhin et. al., 2013; Rahim and Hastuti, 2018), dengan menggunakan teknologi penangkapan berupa mesin tempel (Ele dan Nkang, 2014) dan alat tangkap yang sederhana (Retnowati, 2011). Nelayan tradisional merupakan perikanan skala kecil (Lopes dan Begossi, 2011) sedangkan menurut Undang-undang No. 45 Tahun 2009 tentang perikanan di Indonesia bahwa nelayan tradisional merupakan nelayan kecil dengan ukuran kapal perikanan yang dimilikinya paling besar 5 grosstonase (GT).

Adanya perubahan musim seperti penangkapan dan paceklik (Raodah, 2015; Adili dan Antonia, 2017) di perairan Selat Sulawesi yang berbatasan langsung dengan pesisir Barat Kabupaten Takalar Provinsi Sulawesi Selatan Indonesia mengakibatkan terjadinya perubahan produksi tangkapan nelayan tradisional (Rahim, 2018; Rahim et al., 2018) sehingga berdampak pada pendapatan usaha tangkap.

Pada dasarnya tujuan pembangunan perikanan adalah untuk meningkatkan kesejahteraan nelayan, petani ikan, dan masyarakat pesisir. Tujuan pembangunan perikanan tersebut tertuang dalam Keputusan Menteri Kelautan dan Perikanan Republik Indonesia Nomor Kep.25/Men/2009. Keputusan menteri tersebut diaplikasikan melalui pemberdayaan masyarakat pesisir dengan pengembangan kegiatan ekonomi, peningkatan kualitas dan kuantitas sumberdaya manusia, penguatan kelembagaan sosial ekonomi, dan mendayagunakan sumberdaya kelautan dan perikanan secara optimal dan berkelanjutan. Berdasarkan hal tersebut maka tujuan penelitian ini menganalisis dampak lama melaut, kekuatan mesin tempel, dan karakteristik responden terhadap pendapatan nelayan tangkap tradisional wilayah pesisir di Kabupaten Takalar Provinsi Sulawesi Selatan Indonesia menarik untuk dikaji.

\section{METODE PENELITIAN}

Metode dasar dalam penelitian ini menggunakan metode eksplanatori. Sugiyono (2014) menjelaskan metode eksplanatori merupakan pengkajian hubungan antar variabel melalui pengujian hipotesis. Penelitian ini menganalisis pengaruh lama melaut, kekuatan mesin tempel, dan karakteristik responden terhadap pendapatan nelayan tangkap tradisional wilayah pesisir di Kabupaten Takalar. Macam data dalam penelitian ini berdasarkan dimensi waktu, yaitu data cross-section Tahun 2016. Metode penentuan responden adalah sensus dengan seluruh responden sebanyak 84 nelayan tradisional. Selanjutnya teknik analisis data sebagai berikut:

$\pi \mathrm{NTr}=\beta_{\mathrm{O}} \mathrm{U}^{\beta 1} \mathrm{Pend}^{\beta 2} \mathrm{TK}^{\beta 3} \operatorname{Pglm}^{\beta 4} \mathrm{LM}^{\beta 5} \mathrm{UM}^{\beta 6}{ }_{\mu}$

Untuk memudahkan perhitungan secara matematik persamaan (1), maka digunakan persamaan double log atau logaritma natural (Ln) Gujarati and Porter (2009) sebagai berikut:

$\pi \mathrm{NTr}=\operatorname{Ln} \beta_{\mathrm{O}}+\beta_{1} \operatorname{LnU}+\beta_{2} \operatorname{LnPend}+\beta_{3} \operatorname{LnTK}+$ $\beta_{4} \operatorname{Pglm}+\beta_{5} \operatorname{LnLM}+\beta_{5} \operatorname{LnUM}+\mu$

dimana:

$\pi \mathrm{NTr}:$ Pendapatan Nelayan Tangkap (Rp/trip)

$\beta_{\mathrm{O}} \quad$ : Intersep/konstanta

$\beta 1, \ldots \beta_{5}$ : Koefisien arah regresi

U : Umur (Tahun)

Pend : Pendidikan (Tahun)

TK : Tanggungan keluarga (Jiwa)

Pglm : Pengalaman (Tahun) 
Lm : Lama melaut( Jam )

UM : Ukuran Mesin (PK)

$\mu \quad$ : Error term

Pengukuran goodness of fit dihitung dengan adjusted $\mathrm{R}^{2}$. Menurut Gujarati and Porter (2009) dirumuskan sebagai berikut :

$$
\text { Adjusted } R^{2}=1-\left(1-R^{2}\right) \frac{(n-1)}{(k-1)}
$$

where :

$\begin{array}{ll}\text { Adjusted } \mathrm{R}^{2} & \text { :koefisien determinasi yang } \\ \text { disesuakan } \\ \text { :jumlah variabel yang tidak } \\ \text { termasuk intersep } \\ \mathrm{n} & \text { :jumlah sampel }\end{array}$

Pengujian hipotesis terhadap koefisien regresi secara bersama-sama digunakan uji-F dengan tingkat kepercayaan tertentu, yang menurut Greene (1990) dirumuskan sebagai berikut:

$$
\text { F hitung }=\frac{E S S /(k-1)}{R S S /(n-k)}
$$

Dimana :

$$
\text { Ftabel }[(k-1):(n-k) ; \alpha]
$$

$\alpha$ : tingkat signifikan

Pengujian terhadap koefisien regresi secara individu (parsial) digunakan uji $t$ dengan tingkat kepercayaan tertentu. Menurut Greene (1990) serta Gujarati and Porter (2009) dengan rumus :

$$
\begin{aligned}
& \text { thitung }=\frac{\beta i}{S \beta i} \\
& \text { tabel }[(n-k) ; a / 2]
\end{aligned}
$$

Dimana :

$\beta_{\mathrm{i}} \quad$ : koefisien regresi ke-i

$\mathrm{S} \beta_{\mathrm{i}}$ : standard error koefisien regresi ke-i

Selanjutnya pengujian multikolinearitas (Farrar and Glauber, 1967) dengan metode VIF (variance inflation factor) yang menurut Gujarati and Porter (2009) dirumuskan :

$$
V I F=\frac{1}{1-R_{j}^{2}}
$$

$\mathrm{R}_{j}^{2}$ diperoleh dari regresi auxilary antara variabel independen atau koefisien determinasi antara variabel bebas ke- ${ }_{j}$ dengan variabel bebas lainnya. Jika nilai VIF lebih kecil dari 10 maka tidak terdapat multikolinearitas. Lain halnya pengujian heterokedastisitas dengan park test (Park, 1966) berikut :

$$
\begin{aligned}
\ln e_{i}^{2} & =\ln \sigma^{2}+\beta \ln X_{i}+v_{i} \\
& =\quad \alpha+\beta \ln X_{i}+v_{i}
\end{aligned}
$$

Jika koefisien ( $\beta$ ) tidak signifikan, maka disimpulkan tidak terdapat heterokedastitas karena varian residualnya tidak tergantung dari variabel independen, sebaliknya jika $\beta$ signifikan maka mengandung unsur heterokedastitas karena besar kecilnya varian residual ditentukan oleh variabel independen (Park, 1966; Gujarati and Porter, 2009).

\section{HASIL DAN PEMBAHASAN}

\section{Karakteristik Responden}

Gambaran umum karakteristik responden nelayan tangkap tradisional di Desa Galesong Kota Kecamatan Galesong Kabupaten Takalar Tahun 2016 dikelompokkan berdasarkan umur, pendidikan, jumlah tanggungan keluarga, pengalaman melaut, lama melaut, dan ukuran mesin (Tabel 1).

Tingkat umur mempengaruhi kemampuan nelayan yang berpengaruh terhadap produktivitas berdasarkan kekuatan fisiknya dan pengalaman kerja sebagai nelayan. Tabel 1 menunjukkan bahwa interval umur 30-39 tahun dengan jumlah nelayan sebesar 42 jiwa atau 49,412\%, sedangkan distribusi responden menurut tingkat umur nelayan terkecil berada pada umur $>59$ tahun dengan jumlah nelayan sebesar 3 jiwa atau $3,529 \%$. Selanjutnya seluruh nelayan 
Tabel 1. Identitas Responden Nelayan Tangkap Tradisional di Kabupaten Takalar



Sumber: Analisis Data Primer, 2016 
responden sebanyak 85 atau $100 \quad \%$ menunjukkan umur produktif. Menurut Soukotta (2001) bahwa Perserikatan BangsaBangsa (PBB) mengklasifikasi tenaga kerja yang produktif secara umum berusia 15-64 tahun.

Distribusi responden menurut tingkat pendidikan terakhir terbesar berada di tingkat SD. Jumlah nelayan tersebut sebesar 37 jiwa atau 43,529 \%. Sedangkan distribusi responden terkecil berada di tingkat SMA. Jumlah nelayan sebesar 4 orang atau sekitar $4,706 \%$. Hasil ini sejalan dengan temuan Purwono (2005) rata-rata tingkat pendidikan nelayan di sekitar perairan Selat Madura Jawa Timur adalah tingkat sekolah dasar. Tingkat pendidikan yang rendah merupakan karakteristik penduduk wilayah pesisir (Riptanti, 2005).

Tingkat pengalaman kerja nelayan berbeda-beda. Distribusi responden dengan tingkat pengalaman terbesar berada pada interval 5-14 tahun yaitu sebesar 41 jiwa nelayan atau 48,235\%. Sedangkan tingkat pengalaman melaut nelayan yang terkecil berada diatas 34 tahun yaitu sebesar 5 jiwa nelayan atau 5,882 \%. Hasil ini sejalan dengan temuan Hasan (2006) pengalaman melaut nelayan Maluku Tengah masingmasing diatas 10 tahun $(30,09 \%)$ dan 31 tahun $(70 \%)$.

Distribusi responden nelayan dengan lama melaut terbesar di Desa Galesong Kota Kecamatan Galesong Kabupaten Takalar berada pada interval 7-8 jam. Jumlah persentasenya sebesar 41,176 \%. Sedangkan yang terkecil yaitu diatas 12 jam dengan jumlah nelayan 1 jiwa saja. Jumlah persentasenya juga hanya $1,176 \%$. Ukuran mesin yang digunakan oleh nelayan berbedabeda ukurannya. Masyarakat nelayan lebih dominan menggunakan mesin dengan ukuran 10 PK yaitu sebanyak 44 orang $(51,765 \%)$. Sedangkan yang terkecil jumlahnya adalah nelayan yang menggunakan ukuran mesin diatas 12 PK yaitu 1 orang $(1,176 \%)$.
Pengaruh Lama Melaut, Kekuatan Mesin Tempel, dan Karakteristik Responden Terhadap Pendapatan Nelayan Tangkap Tradisional

Analisis pengaruh lama melaut, kekuatan mesin tempel, dan karakteristik responden terhadap pendapatan nelayan tangkap tradisional wilayah pesisir di Kabupaten Takalar selain menggunakan model analisis regresi berganda juga menggunakan pengujian asumsi klasik multikolinearitas dan heterokedastisitas. Hasil pengujian menunjukkan tidak terjadi multikolinearitas, atau kolinearitas ganda dan heterokedastisitas (Tabel 2).

Pada pengukuran ketepatan model dari nilai adjusted $\mathrm{R}^{2}$ menunjukkan variabel independen pada model fungsi pendapatan nelayan tangkap yang disajikan dapat menjelaskan masing-masing yaitu besarnya persentase sumbangan variabel bebas (umur, Pendidikan terakhir, tanggungan keluarga, pengalaman, lama melaut, dan kekuatan mesin tempel) sebesar 63,2 \% terhadap variasi (naik-turunnya) variabel tidak bebas sedangkan lainnya masing-masing sebesar $36,8 \%$ merupakan sumbangan dari faktor lainnya yang tidak masuk dalam model (Tabel 2).

Hasil uji-F menunjukkan bahwa fungsi pendapatan nelayan tangkap berpangurih signifikan pada tingkat kesalahan 1\%. Hal tersebut dapat diartikan bahwa seluruh variabel independen secara bersama-sama (simultan) berpengaruh nyata terhadap fungsi pendapatan nelayan tangkap tradisional. Selanjutnya pengaruh secara individu (parsial) dari masing-masing variabel independen digunakan uji-t dan nilai koefisien regresi pada (Tabel 2)

Variabel umur nelayan sebagai karakteristik responden tidak berpengaruh terhadap pendapatan nelayan tangkap di Desa Galesong Kota Kecamatan Galesong Kabupaten Takalar. Secara empiris rata-rata nelayan Kabupaten Takalar lebih di usia 3039 tahun yaitu 42 nelayan. Sedangkan pada 
umur $>40$ tahun lebih sedikit yaitu 33 nelayan saja. Selain itu, diamati bahwa nelayan yang sudah berada pada usia lanjut produksinya lebih kecil karena mereka tidak kuat melakukan perjalanan melaut yang lama. Umumnya mereka hanya melakukan perjalanan melaut 5-6 jam.

Variabel karakteristik responden berupa pendidikan terakhir tidak berpengaruh terhadap pendapatan nelayan tangkap di Desa Galesong Kota Kecamatan Galesong Kabupaten Takalar. Temuan ini sejalan dengan penelitian Harahap (2003) di Kelurahan Nelayan Indah Kecamatan Medan Labuhan Kota Medan, akan tetapi tidak sejalan dengan penelitian Adili and Antonia (2017) di Tanzania pada Samudra Hindia bahwa Pendidikan berpengaruh terhadap pendapatan nelayan.

Pendidikan terakhir nelayan di Kabupaten Takalar tidak berpengaruh signifikan karena pada umumnya masyarakat mendapat pengetahuan melaut hanya dari pengetahuan turun-temurun dari orang tua mereka yang umumnya juga berprofesi sebagai nelayan tangkap. Hal ini dibuktikan secara empiris dari jumlah distribusi responden yang paling banyak yaitu nelayan yang hanya tamat Sekolah Dasar (SD) saja sebanyak 37 nelayan. Walaupun menurut Riptanti (2005) mengemukakan bahwa pendidikan formal dapat dijadikan salah satu indikator mengukur produktivitas, semakin tinggi tingkat pendidikan yang dimilikinya semakin tinggi pula produktivitas dan kemampuan mengelola usaha tangkap dan berani mengambil risiko dalam usahanya.

Tanggungan keluarga dan pengalaman melaut (karakteristik responden) juga tidak berpengaruh terhadap pendapatan nelayan di Kabupaten Takalar. Hasil ini tidak sejalan dengan Primyastanto et al. (2013) bahwa pengalaman melaut juga berpengaruh positif terhadap perubahan pendapatan nelayan Payang di Selat Madura. Secara empiris frekuensi jumlah tanggungan keluarga yang paling banyak adalah yang berjumlah 1-2 orang tanggungan yaitu sebesar 48 responden $(56,471 \%)$. Sebaliknya frekuensi yang paling kecil adalah dengan jumlah diatas 4 orang yaitu sebesar 8 reponden $(9,412 \%)$, sedangkan pengalaman melaut terbesar berada antara 5-14 tahun yaitu sebesar 41 orang nelayan $(48,235 \%)$. Sedangkan tingkat pengalaman melaut nelayan yang terkecil berada diatas 34 tahun yaitu sebesar 5 orang

Tabel 2. Pengaruh Lama Melaut, Kekuatan Mesin Tempel, dan Karakteristik Responden terhadap Pendapatan Nelayan Tangkap Tradisional Wilayah Pesisir Di Kabupaten Takalar.

\begin{tabular}{|c|c|c|c|c|c|c|}
\hline \multirow[b]{2}{*}{ Variabel Independen } & \multirow[b]{2}{*}{ T.H } & \multirow{2}{*}{$\begin{array}{c}\text { Koefisien } \\
(\beta)\end{array}$} & \multirow[b]{2}{*}{ t-hit. } & \multirow[b]{2}{*}{ t-sig } & \multicolumn{2}{|c|}{ Uji Asumsi Klasik } \\
\hline & & & & & $V I F$ & Koef. Park Test \\
\hline$\overline{\text { Umur }}$ & - & $0,022 \mathrm{~ns}$ & 0,122 & 0,913 & 3,027 & $0,800 \mathrm{~ns}$ \\
\hline Pendidikan Terakhir & - & $-0,108 \mathrm{~ns}$ & $-1,121$ & 0,266 & 1,108 & $0,559 \mathrm{~ns}$ \\
\hline Tanggungan Keluarga & - & $-0,005 \mathrm{~ns}$ & $-0,085$ & 0,932 & 1,183 & $0,529 \mathrm{~ns}$ \\
\hline Pengalaman & + & $-0,054 \mathrm{~ns}$ & $-0,569$ & 0,571 & 2,851 & $0,501 \mathrm{~ns}$ \\
\hline Lama Melaut & + & $0,526 * * *$ & 3,892 & 0,000 & 2,024 & $0,179 \mathrm{~ns}$ \\
\hline Ukuran Mesin & + & $0,891 * * *$ & 4,864 & 0,000 & 2,217 & $0,191 \mathrm{~ns}$ \\
\hline Konstanta & & & & & & 9,147 \\
\hline F-hitung & & & & & & 23,944 \\
\hline Adjusted $R^{2}$ & & & & & & 0,632 \\
\hline $\mathrm{N}$ & & & & & & 85 \\
\hline
\end{tabular}

Sumber : Analisis Data Primer Setelah diolah, 2016

Keterangan :

TH : Tanda Harapan

*** : Taraf signifikansi atau kesalahan 0,01 (1 persen) atau tingkat kepercayaan 99 persen

ns : Tidak signifikan 
nelayan $(5,882 \%)$.

Variabel lama melaut berpengaruh positif dan signifikan terhadap pendapatan nelayan tangkap di Kabupaten Takalar dengan nilai koefisien regresi sebesar 0,526 yang artinya yaitu setiap penambahan lama melaut sebanyak 1 jam melaut akan meningkatkan pendapatan nelayan tangkap sebesar 0,526 persen. Secara empiris rata-rata lama melaut terbesar di Desa Galesong Kota Kecamatan Galesong Kabupaten Takalar berada pada interval 7-8 jam (41,176 \%). Sedangkan yang terkecil yaitu diatas 12 jam dengan jumlah nelayan 1 orang saja $(1,176 \%)$.

Variabel ukuran kekuatan mesin tempel berpengaruh positif terhadap pendapatan nelayan tangkap di Kabupaten Barru, artinya setiap penambahan 1 PK (power Knot) ukuran kekuatan mesin tempel maka pendapatan nelayan tangkap naik sebesar 0,89 . Temuan ini sejalan dengan penelitian Jabri et al. (2013) di Oman bahwa kekuatan mesin mempengaruhi perubahan pendapatan nelayan skala kecil. Secara empiris masyarakat nelayan Kabupaten Takalar lebih dominan menggunakan mesin dengan ukuran 10 PK yaitu sebanyak 44 orang $(51,765 \%)$. Sedangkan yang terkecil jumlahnya adalah nelayan yang menggunakan ukuran mesin diatas 12 PK yaitu 1 orang $(1,176 \%)$.

\section{SIMPULAN DAN SARAN}

Berdasarkan hasil penelitian, ditemukan bahwa lama melaut dan ukuran kekuatan mesin tempel berpengaruh positif terhadap pendapatan nelayan tangkap tradisional di Kabupaten Takalar, sedangkan umur, pendidikan terakhir, tanggungan keluarga, dan pengalaman melaut tidak berpengaruh terhadap pendapatan nelayan tangkap tradisional

Berdasarkan hasil temuan penelitian yang telah dilakukan, maka variabel lama melaut dan ukuran mesin dapat direkomendasikan kepada pemerintah daerah Kabupaten Takalar untuk memberikan bantuan langsung atau kredit berupa mesin tempel dengan ukuran yang lebih besar seperti 20 PK dengan kekuatan Kapal 30 - 50 GT untuk menjangkau fishing ground dan dapat mencari ikan lebih lama di lautan lepas utuk keberlanjutan usahanya.

\section{DAFTAR PUSTAKA}

Adili, Z. and M. Antonia. 2017. Determinants influencing fishing income to the coastal households of Indian Ocean. Oceanografy and Fisheries. 4(3):1-6.

Barnes-Mauthe M., K.K.L. Oleson and B. Zafindrasilivonona. 2013. The total economic value of small-scale fisheries with a characterization of post-landing trends: an application in Madagascar with Global Relevance, Journal of Fisheries Research 147: 175-185.

Ele, I.E. and M.O. Nkang. 2014. Analysis of Production Determinants and Technical Efficiency in Crayfish Production in the Lower Cross River Basin. Nigeria, Journal of Research In Humanities and Social Science. 2(11): 30-36.

Gujarati, D.N. and D.C. Porter, 2009, Basic econometrics, $5^{\text {th }}$ edition.McGraw-Hill, American.

Gebremedhin S, M. Budusa, M. Mingist, and J. Vijverberg. 2013. Determining Factors for Fishers' Income: The Case of Lake Tana, Ethiopia. International Journal of Current Research. 5 (5):1182-1186.

Greene, W.H. 1990. Econometric analysis (second edition). Macmilan Publishing Company, Toronto.

Hasan, N. 2006. Produksi dan distribusi pendapatan usaha penangkapan ikan di Maluku Tengah, Tesis. Program Studi Ekonomi Pertanian, Universitas Gadjah Mada, Jogjakarta.

Israel D.C., E.Y. Adan, N.F. Lopez, and J.C. Castro. 2004. Perceptions of fishermen households on the long- 
term impact of coastal resources management in Panguil Bay Philippine. Journal of Development. 31 (1):107-134.

Jabri, O.A., R. Collins, X. Sun, A. Omezzine, and R. Belwal. 2013. Determinants of small-scale fishermen's income on Oman's batinah coast. Marine Fisheries Review. 73(3):21-32. doi: dx.doi.org/10.7755/MFR.75.3.3 .

Keputusan Menteri Kelautan dan Perikanan Republik Indonesia Nomor Kep.25/Men/2009. Tentang Pedoman Pelaksanaan Program Nasional Pemberdayaan Masyarakat Mandiri Kelautan Dan Perikanan. Jakarta.

Lopes, P.F.M., and A. Begossi. 2011. Decision-making processes by smallscale fishermen on the southeast coast of Brazil. Journal Fisheries Management And Ecology. 2(3) :1-11.

Pameroy R.S., and N.L Andrew. 2011. SmaleScale fisheries management: frameworks and approaches for the developping world. CPI Antony Rome, Chippenham.

Purwono, G.S. 2005. Strategi bertahan hidup nelayan terhadap perubahan kondisi daerah penangkapan ikan di Selat Madura. Disertasi. Program Studi Kependudukan Universitas Gadjah Mada Jogjakarta.

Primyastanto, M., A. Efani, Soemano, dan S. Muhammad. 2013. faktor yang berpengaruh terhadap pendapatan dan pengeluaran nelayan payang di Selat Madura. Jurnal Wacana. 16(1): 1-3.

Rahim, A. 2018. The empowerment strategy of the traditional fisherman's wives in the coastal area of Barru Regency, South Sulawesi. Journal of Socioeconomics and Development, $1(1), 1-6$.

Rahim, A., and Hastuti, D.R.D. 2018. Applied multiple regression method with exponential functions: an estimation of traditional catch fishermen household income. Journal of Physics : Conference Series. 1028(1), 1-8.

Rahim, A., Hastuti, D.R.D., Ningsih, S.R., Mardia, Nuryanti, D.M., Patta, A.A., Yatim, H., and Hayat, N.Z. 2018. The influence of marketing volume and marketing channel on fresh Tiger Shrimp marketing margin. Indonesian Journal of Fundamental Sciences. 4(1):16-23.

Raodah. 2015. Respon nelayan tradisional terhadap perubahan musim di Kelurahan Lappa Kabupaten Sinjai. Jurnal Walasuji 6(1) : 225-238.

Riptanti, E.W. 2005. Karakteristik dan persoalan ekonomi masyarakat petani dan nelayan pada Kawasan Pantai di Torosiaje Kabupaten Pohuwatu. Caraka Tani (Jurnal Ilmu-ilmu Pertanian). 22(2):55-68.

Retnowati E. 2011. Nelayan indonesia dalam pusaran kemiskinan struktural (perspektif sosial, ekonomi, dan hukum), Jurnal Perspektif, XVI (3) : 149-159.

Soukotta, L.M., 2001, Analisis biaya dan pendapatan berbagai alat tangkap di Kabupaten Maluku Tengah. Tesis. Program Studi Ekonomi Pertanian Universitas Gadjah Mada, Jogjakarta.

Sugiyono. 2014. Metode Penelitian Kuantitatif Kualitatif dan R\&D (Cetakan Ke 20). Bandung: Alfabeta.

Winarti L., dan R. Permadi. 2015. Distribusi pendapatan rumah tangga nelayan (studi kasus di Desa Sungai Bakau Kecamayan Seruyan Hilir Timur dan Desa Sungai Undang Kecamatan Seruyan Hilir Kabupaten Seruyan). Jurnal Ziraa'ah. 40(3):203-21. 